\title{
Ongoing activities to influence the prescribing of proton pump inhibitors within the Scottish National Health Service: their effect and implications
}

\author{
${ }^{*}$ Brian Godman $1,2,3$, Amanj Kurdi ${ }^{1,4}$, Holly McCabe ${ }^{5}$, Sean MacBride-Stewart ${ }^{6}$, Axel Leporowski ${ }^{5}$, \\ Simon Hurding ${ }^{7}$, Marion Bennie ${ }^{1}$, Alec Morton ${ }^{5}$ \\ ${ }^{1}$ Strathclyde Institute of Pharmacy and Biomedicial Sciences, University of Strathclyde, Glasgow, \\ United Kingdom. Email: Brian.Godman@strath.ac.uk; amanj.baker@ strath.ac.uk; \\ marion.bennie@strath.ac.uk \\ ${ }^{2}$ Division of Clinical Pharmacology, Karolinska, Karolinska Institutet, Stockholm, Sweden. Email: \\ Brian.Godman@ki.se \\ ${ }^{3}$ Department of Public Health Pharmacy and Management, School of Pharmacy, Sefako Makgatho \\ Health Sciences University, Garankuwa, South Africa \\ ${ }^{4}$ Department of pharmacology, College of Pharmacy, Hawler Medical University, Erbil, Iraq \\ ${ }^{5}$ Department of Management Science, Strathclyde Business School, University of Strathclyde, \\ Glasgow, United Kingdom. Email: axel.leporowski@strath.ac.uk; alec.morton@strath.ac.uk; \\ holly.mccabe.2013@uni.strath.ac.uk \\ ${ }^{6}$ Pharmacy and Prescribing Support Unit, National Health Service Greater Glasgow and Clyde (NHS \\ GGC), Glasgow, UK. Email: Sean.MacBride-Stewart@ggc.scot.nhs.uk \\ 6Primary Care Unit, NHS Scotland, Edinburgh, UK. Email: Simon.Hurding@gov.scot
}

\begin{abstract}
*Author for correspondence: Brian Godman, Strathclyde Institute of Pharmacy and Biomedical Sciences, University of Strathclyde, Glasgow G4 ORE, United Kingdom. Email:

brian.godman@strath.ac.uk. Telephone: 0141548 3825. Fax: 01415522562 and Division of Clinical Pharmacology, Karolinska Institute, Karolinska University Hospital Huddinge, SE-141 86, Stockholm, Sweden. Email: Brian.Godman@ki.se. Telephone + 468 58581068. Fax + 46859581070
\end{abstract}

Keywords: PPIs, Scottish NHS, expenditure, reforms, drug utilisation, generics

(Accepted for publication - GABI Journal)

\begin{abstract}
Introduction: There has been a considerable increase in the use of proton pump inhibitors (PPIs) in recent years due to their effectiveness versus $\mathrm{H} 2$ antagonists. This includes reducing $\mathrm{Gl}$ bleeds in patients at risk. However, there are concerns with their long term use and potential costs. Costs can be reduced with increased prescribing of low cost generic PPIs. Aims: To analyse the influence of multiple demand-side measures in Scotland in recent years to increase the prescribing of low cost generic PPIs as well as encourage the prescribing of lower strength PPIs. Methods: Documenting utilization (mainly items dispensed) and expenditure in Scotland from 2001 to 2017 using health authority databases combined with documenting the multiple initiatives and measures both nationally and regionally. Results: The multiple measures in Scotland ensured high International non-proprietary name prescribing (up to $100 \%$ for some PPIs) as well as the prescribing of generic versus patented PPIs, with costs of generic PPIs as low as $8.5 \%$ of their pre-patent loss prices. Overall, total expenditure on PPIs in Scotland was 66.7\% lower in 2017 at GB£18.83million compared to 2001 levels. This was despite a 3.06-fold increase in PPI utilization during this period. The savings were driven by the increasing use of generic omeprazole and lansoprazole versus patent protected PPIs. There was also a reduction in the prescribing of high strength PPIs during this period. Conclusion: Multiple initiatives in Scotland in recent years have reduced expenditure on PPIs despite appreciably increased utilisation. Multiple initiatives have also helped to reduce the prescribing of higher strength PPIs. This is an exemplar to other countries seeking to enhance their prescribing efficiency.
\end{abstract}

\section{Introduction}

With ageing populations, the increasing prevalence of chronic diseases, and polypharmacy, the proton pump inhibitors (PPIs) have become one of the most prescribed medicines among Western countries (1-4). We are also seeing increased use of PPIs among Central and Eastern European (CEE) countries (2). However, this is not universal as there are prescribing restrictions and copayments for PPIs in some CEE countries such as Lithuania and Serbia, which appreciably limited their use versus Western European countries $(2,5)$. 
Upper gastrointestinal (GI) symptoms have a substantial impact on patients as well as healthcare utilisation across countries. For instance, up to $10 \%$ of general practitioner (GP) consultations in the UK are for dyspepsia (6). The prescribing of PPIs has increased in recent years with studies showing them to be more effective than $\mathrm{H} 2$ antagonists in both preventing and healing ulcers as well as reducing GI bleeds (7-13). This is important if patients are on long term treatment such as NSAIDs for pain or a combination of antiplatelet and anti-coagulant treatment (14-16). In the early 2000s, there were also concerns at the extent of GI bleeding causing admissions to hospitals in the UK with encouragement of greater use of PPIs $(17,18)$, although they still occur leading to over 9000 deaths annually in the UK (18).. As a result of these various factors, omeprazole was the most frequently prescribed medicine in Scotland in 2014 and 2015 (19). The high use of PPIs has also been seen in other countries and sectors $(3,20-25)$, with their usage enhanced in some countries by non-guideline prescribing (1).

However, there are concerns that long term use of PPIs can have patient safety issues $(1,26)$. Safety concerns include increasing the rate of community acquired pneumonia, increasing the number of fragility fractures, as well as increasing the number of clostridium difficile infections (CDI) possibly due to changes in the gut microbiomes. In addition, increasing the number of norovirus infections as well as increasing the extent of chronic kidney disease and hypomagnesemia (19, 20, 27-37). These concerns have resulted in guidance from the Greater Glasgow and Clyde Health Board in Scotland and others to suggest that patients on PPIs long term, and at risk of osteoporosis, should have an adequate intake of calcium and vitamin D $(19,38)$. Patients on PPIs long term should also have their serum magnesium levels regularly checked especially if they are taking digoxin or other medicines known to cause hypomagnesaemia (19). PPIs should also be stopped where possible in those patients with suspected or actual CDIs $(19,39,40)$. Such considerations though have to be balanced against the undoubted effectiveness of PPIs in preventing and healing ulcers, controlling symptoms of dyspepsia and heartburn, as well as reducing hospital admissions and deaths due to GI bleeds.

Concerns with the possible adverse effects of long-term PPIs resulted in guidance to GPs in Scotland from mid to late 2000s onwards to prescribe the lowest possible dose, and also generally to review patients on PPIs long term at least annually $(27,41-43)$. This builds on earlier advice from NHS Scotland to enhance the prescribing of maintenance doses of PPIs rather than healing doses whenever possible as a measure of the quality of prescribing (44). The proportion of high strength versus low strength PPIs has subsequently been monitored and benchmarked between the different Regional Health Boards in Scotland as an indicator of the quality of GP prescribing, with GPs encouraged, as mentioned, to regularly review patients prescribed high strength PPIs $(14,16,27,45$, 46). Quality Indicators (process) discouraging the prescribing of high strength PPIs were also included in the Scottish National Therapeutic Indicators (NTI) list in 2012; however, they were dropped from $2013(27,45)$ onwards to just concentrate on overall PPI utilisation. This change was because the Scottish government advisers, chaired by two of the co-authors, believed that the majority of potential reductions in the strength of PPIs prescribed by GPs had already taken place by 2013 , and there was limited additional benefit to carry on with this NTI compared with other more important NTIs. If they wish to prescribe higher strength omeprazole, GPs were encouraged to prescribe $2 \times 20 \mathrm{mg}$ capsules omeprazole rather than one $40 \mathrm{mg}$ capsule as this could be up to $60 \%$ less expensive.

Increased prescribing of PPIs is a concern where there is limited use of low cost generic PPIs compared with appreciably more expensive patented PPIs as this will drive up ambulatory care expenditure without improving patient outcomes with all PPIs seen as essentially similar at comparable therapeutic doses (47). Expenditure on PPIs in countries where there have been limited initiatives to increase the prescribing of multiple sourced (generic) PPIs versus on patent PPIs has been up to ten times greater when adjusted for population size compared with European countries who actively promoted the preferential prescribing of generic PPIs through multiple initiatives and measures (47).

Such differences in expenditure are a major concern where resources are limited as this will reduce available resources to be spent on other priority disease area. To address this, the Scottish government, coupled with the Regional Health Boards in Scotland, introduced a range of measures and initiatives in recent years to encourage the prescribing of multiple sourced products where this does not compromise care $(48,49)$. These measures were addition to existing initiatives in Scotland to encourage the prescribing of lower dose PPIs as well as encourage international non-proprietary (INN) prescribing. Initiatives to enhance INN prescribing in Scotland included education in medical 
schools, IT support systems and prescribing targets (49-51), with the prices of generic PPIs as low as $9 \%$ of pre-patent loss originator prices (49). Such activities are necessary in the UK to fully realise the savings from the availability of generics as community pharmacists are currently banned from substituting an originator medicine with a generic if the physician prescribes the originator (52). This is unlike for instance the situation in Sweden where there is compulsory generic substitution or France where pharmacists have agreed targets for substitution $(53,54)$. There is also no obligation for the originator company in the UK to lower its prices to be reimbursed once generics become available as there is no internal reference pricing system. This is unlike a number of other European countries (55). Low prices for generics in the UK followed the introduction of the ' $M$ ' and ' $W$ ' scheme (Manufacturer and Wholesaler) in April 2005, which enhanced transparency in the prices of generics (50). Prior to this, prices of generics were less transparent in the UK as witnessed by generic manufacturers offering discounts of up to $80 \%$ or more on their list prices to increase their sales volumes (50). There are also no concerns with INN prescribing among GPs in the UK apart from a limited number of situations, unlike the situation in other European countries $(52,56-59)$.

Initiatives to encourage the prescribing of multiple sourced (generic) PPIs first line in Scotland versus patented PPIs included education, prescribing targets and financial incentives $(42,48,49)$. Generic PPIs have been endorsed over originators and patented PPIs in view of the considerable cost differences and limited differences in effectiveness between them at equivalent doses, with generic omeprazole and generic lansoprazole typically endorsed over other generic PPIs in Scotland as they had lower prices $(19,27,41,42,49,60,61)$. These combined measures have resulted in considerable savings in the past in Scotland (49). This is similar to the multiple activities that have been instigated nationally and regionally in Scotland to enhance prescribing efficiency for lipid lowering medicines with similar results (62).

There has also been Scottish Guidelines (SIGN - Scottish Intercollegiate Guidelines Network) issued in 2003 educating physicians on the management of dyspepsia including PPIs (49).

In this paper, we will seek to further analyse the influence of these multiple activities instigated by the Scottish Government combined with the Health Boards in Scotland to improve efficient prescribing of PPIs in ambulatory care as well as the prescribing of lower strength PPIs. We will also evaluate the influence of changing PPI prices on the prescribing mix. This builds on our previous publications regarding policies to influence the prescribing of multiple sourced PPIs in Scotland $(48,49)$. We have concentrated on ambulatory care as there is limited prescribing of PPIs among hospital in-patients versus ambulatory care in Scotland (49). The findings will be used to provide guidance to countries struggling to provide comprehensive healthcare in the face of growing resource pressures driven by ageing populations with more complex diseases.

\section{Methodology}

To assess the utilisation and prescribing patterns of PPIs in ambulatory care in Scotland, we analysed the prescription costs analysis (PCA) database (63). This database is compiled by the Information Services Division (ISD) of NHS Scotland from 2001 to 2017 (63). This is an open source data set collecting data on the utilization and expenditure of medicines dispensed in community pharmacies in Scotland. It is a robust dataset that is regularly audited and covers the whole of Scotland rather than a selection of community pharmacies. NHS Scotland is a universal healthcare system serving the entire Scottish population $(49,62)$, with currently no co-payment for medicines in Scotland.

Between 2001 and 2017, the Scottish NHS made 5 PPIs available to be prescribed. These included omeprazole, lansoprazole, pantoprazole, rabeprazole and esomeprazole. Information extracted from the PCA between 2001 and 2017 included: the generic name, commercial name(s), formulation(s), drug strength(s), number of dispensed units, cost per unit and total gross expenditure. All costs are depicted in Great Britain pounds (GB£s) and depict the gross ingredient costs (GIC) and cost per item for the medicines dispensed. No adjustment for inflation for the prices was made. This is in line with previous studies due to the rapid reduction in prices in the UK once originators such as the PPIs became available as generics (47-49).

Whilst NHS Scotland routinely uses defined daily doses (DDDs) as well as DIDs (DDDs/ 1000 inhabitants/ day) when discussing and presenting utilization data $(16,27)$, which is in line with international guidance $(27,45,64)$, we typically used items dispensed in community pharmacies in 
this analysis, although some analyses were undertaken with DDDs. This is because we wanted to track actual prescriptions, especially with physicians being encouraged to prescribe lower strength PPIs. In the case of patients with chronic diseases such as GERD or dyspepsia, a prescription is usually for 28 or 56 days. However, there has been tendency in recent years for physicians to increase the length of a prescription to help with their growing workloads (62). However, cognizant of the need to regularly review the strength of PPIs prescribed for patients on long term use (19). We recognize this may influence the analysis of prescribing volumes when compared with DDDs, as well as make comparisons across countries difficult. However, our primary aim was an evaluation of prescribing practices in Scotland.

For each PPI and year, total costs, the total number of dispensed and the expenditure they represent to NHS Scotland were calculated with the totals based on summation of individual items dispensed. In addition, DDDs were also used when researching the influence of different initiatives to encourage the prescribing of lower strength PPIs. The DDDs were calculated based on the number of packs dispensed and their strength (64). A sub-analysis of the extent of prescribing of generic versus originator PPIs was also undertaken again based on items dispensed. This information was plotted over time in years. The date at which each PPI became available as a generic in Scotland was also obtained from an internal NHS database. The ongoing activities within the Health Boards to improve the quality and efficiency of PPI prescribing have been collated using the 4E methodology, building on previous findings: Education, Engineering, Economics and Enforcement $(48,49,65)$. Education refers to initiatives such as guidelines and academic detailing; engineering refers to organizational or managerial interventions such as prescribing indicators; economics refers to financial incentives for the prescriber; and enforcement refers to specific regulations from health authorities such as prescribing restrictions or compulsory generic substitution $(48,54,65,66)$. However, enforcement is very rare in Scotland unlike some other European countries including Austria, Finland, Norway and Sweden (66-69).

No sophisticated analysis such as time-series analyses was undertaken due to the multiple measures and interventions instigated between 2001 and 2017, and the associated problems with conducting such analyses in these circumstances (70).

\section{Results}

Of the 5 PPIs included in this study, none were generically available in 2001. By the end of 2012, all 5 PPIs were available as generics with different formulations and strengths (Table 1).

Table 1 - PPIs and their patent expiration date in Scotland from 2001 to 2017

\begin{tabular}{|l|c|c|c|}
\hline \multicolumn{1}{|c|}{ Generic name } & $\begin{array}{c}\text { Commercial name } \\
\text { (Originator) }\end{array}$ & $\begin{array}{c}\text { Number of } \\
\text { formulations and } \\
\text { strengths }\end{array}$ & $\begin{array}{c}\text { Year of patent } \\
\text { expiration }\end{array}$ \\
\hline Esomeprazole & Nexium $\AA$ & 11 & 2009 \\
\hline Lansoprazole & Zoton $\AA$ & 10 & 2005 \\
\hline Omeprazole & Losec $\AA$ & 31 & 2002 \\
\hline Pantoprazole & Pantaloc Control $\circledast$ & 5 & 2009 \\
\hline Rabeprazole & Pariet $₫$ & 4 & 2012 \\
\hline
\end{tabular}

A variety of measures were undertaken between 2000 and 2017 to enhance the quality and efficiency of PPI prescribing (Table 2). 
Table 2 - Summary of principal demand-side measures introduced in Scotland between 2001 and 2017 that influenced the utilization of PPIs $(16,19,27,42-45,48,49,51,61,71,72)$

\begin{tabular}{|c|c|c|}
\hline Measure & $\begin{array}{l}\text { National or } \\
\text { Regional }\end{array}$ & Initiative \\
\hline \multirow{7}{*}{ Education } & National & $\begin{array}{l}\text { Physicians typically trained in medical school to } \\
\text { prescribe by INN name with follow up in the community } \\
\text { coupled with IT systems. Follow up includes the use of } \\
\text { decision support software as well as monitoring the } \\
\text { extent of INN prescribing }\end{array}$ \\
\hline & National & $\begin{array}{l}\text { - National guidance and guidelines (SIGN) for dyspepsia } \\
\text { (withdrawn in 2015) }\end{array}$ \\
\hline & National & $\begin{array}{l}\text { Maintenance doses encouraged over healing doses of } \\
\text { PPIs through education and benchmarking (engineering) } \\
\text { as part of initiatives across Scotland to improve the } \\
\text { quality of prescribing }\end{array}$ \\
\hline & $\begin{array}{l}\text { National and } \\
\text { Regional }\end{array}$ & $\begin{array}{l}\text { - Lower strength PPIs recommended over higher strength } \\
\text { PPIs in view of concerns with the long term safety of } \\
\text { PPIs }\end{array}$ \\
\hline & $\begin{array}{l}\text { National and } \\
\text { Regional }\end{array}$ & $\begin{array}{l}\text { Regular review of patients on long term PPIs especially } \\
\text { those with polypharmacy and/or at risk of osteoporosis, } \\
\text { CDI and concerns with magnesium levels }\end{array}$ \\
\hline & $\begin{array}{l}\text { National and } \\
\text { Regional }\end{array}$ & $\begin{array}{l}\text { - Esomeprazole not recommended for use in NHS } \\
\text { Scotland due to price differences with other PPIs }\end{array}$ \\
\hline & Regional & $\begin{array}{l}\text { Regional formularies for PPIs such as the Lothian and } \\
\text { Greater Glasgow and Clyde formularies advocating } \\
\text { generic omeprazole. Lothian and Greater Glasgow and } \\
\text { Clyde subsequently advocating both generic } \\
\text { lansoprazole and omeprazole following generic } \\
\text { availability of both PPls, which has continued }\end{array}$ \\
\hline \multirow{4}{*}{ Engineering } & Regional & $\begin{array}{l}\text { - Indicators to enhance the prescribing of low cost PPIs } \\
\text { versus single sourced PPIs (withdrawn once the principal } \\
\text { PPIs were available as generics) }\end{array}$ \\
\hline & National & $\begin{array}{l}\text { - Benchmarking potential savings from increased generic } \\
\text { prescribing }\end{array}$ \\
\hline & $\begin{array}{l}\text { National and } \\
\text { Regional }\end{array}$ & $\begin{array}{l}\text { Indicators (quality) and benchmarking encouraging the } \\
\text { prescribing of lower strength PPIs }\end{array}$ \\
\hline & Regional & $\begin{array}{l}\text { - } \begin{array}{l}\text { Prescribing targets for esomeprazole (e.g. }<4 \% \text { of all PPI } \\
\text { prescriptions) }\end{array}\end{array}$ \\
\hline Economics & Regional & - $\quad$ Financial based prescribing incentive schemes \\
\hline $\begin{array}{l}\text { Enforcement } \\
\text { (Restrictions) }\end{array}$ & $\begin{array}{l}\text { National and } \\
\text { Regional }\end{array}$ & $\begin{array}{l}\text { Esomeprazole not recommended for use in NHS } \\
\text { Scotland due to price differences with other PPIs }\end{array}$ \\
\hline
\end{tabular}

Total PPI utilisation increased 3.06-fold between 2001 and 2017, rising from 1.800 million items dispensed in 2001 to 5.501 million items in 2017. The increase in utilisation has been driven predominantly by increased utilisation of omeprazole and lansoprazole with limited utilisation of the other PPIs (Figure 1). 
Figure 1 - Total utilisation of PPIs in Scotland between 2001 and 2017 (Items dispensed ${ }^{*}$ ) [Source ISD Scotland - (63)]

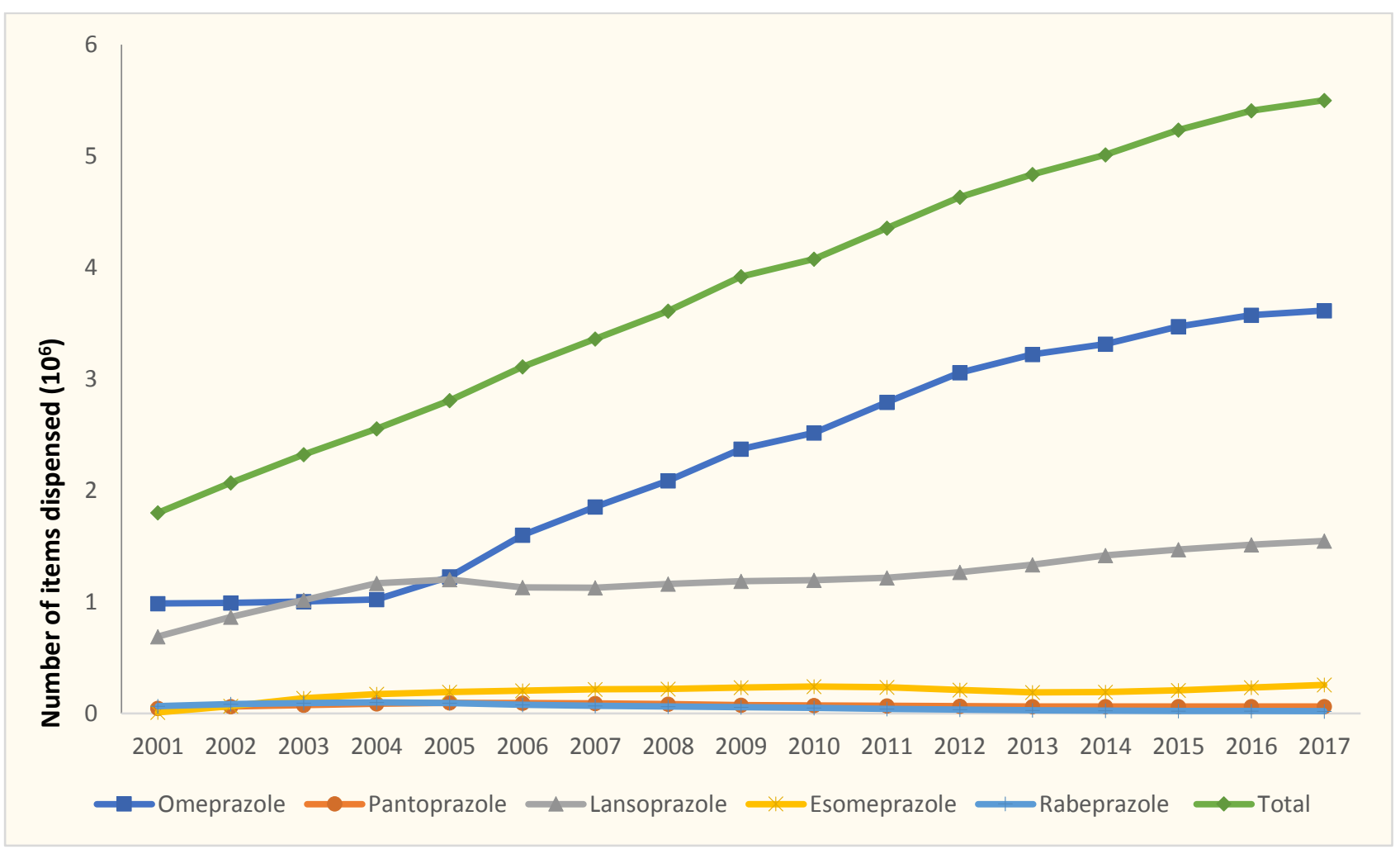

${ }^{*}$ Items $=$ count of the prescription items, i.e. the number of times a medicine is written onto a prescription form and dispensed in community pharmacies

Concurrent with this, total PPI expenditure fell by $66.7 \%$ between 2001 and 2017 from GB£ 56.486 million in 2001 to GB£18.832 million in 2017 (Figure 2). 
Figure 2 - Total expenditure (GBE) on PPIs in Scotland between 2001 and 2017 [Source ISD Scotland - (63)]

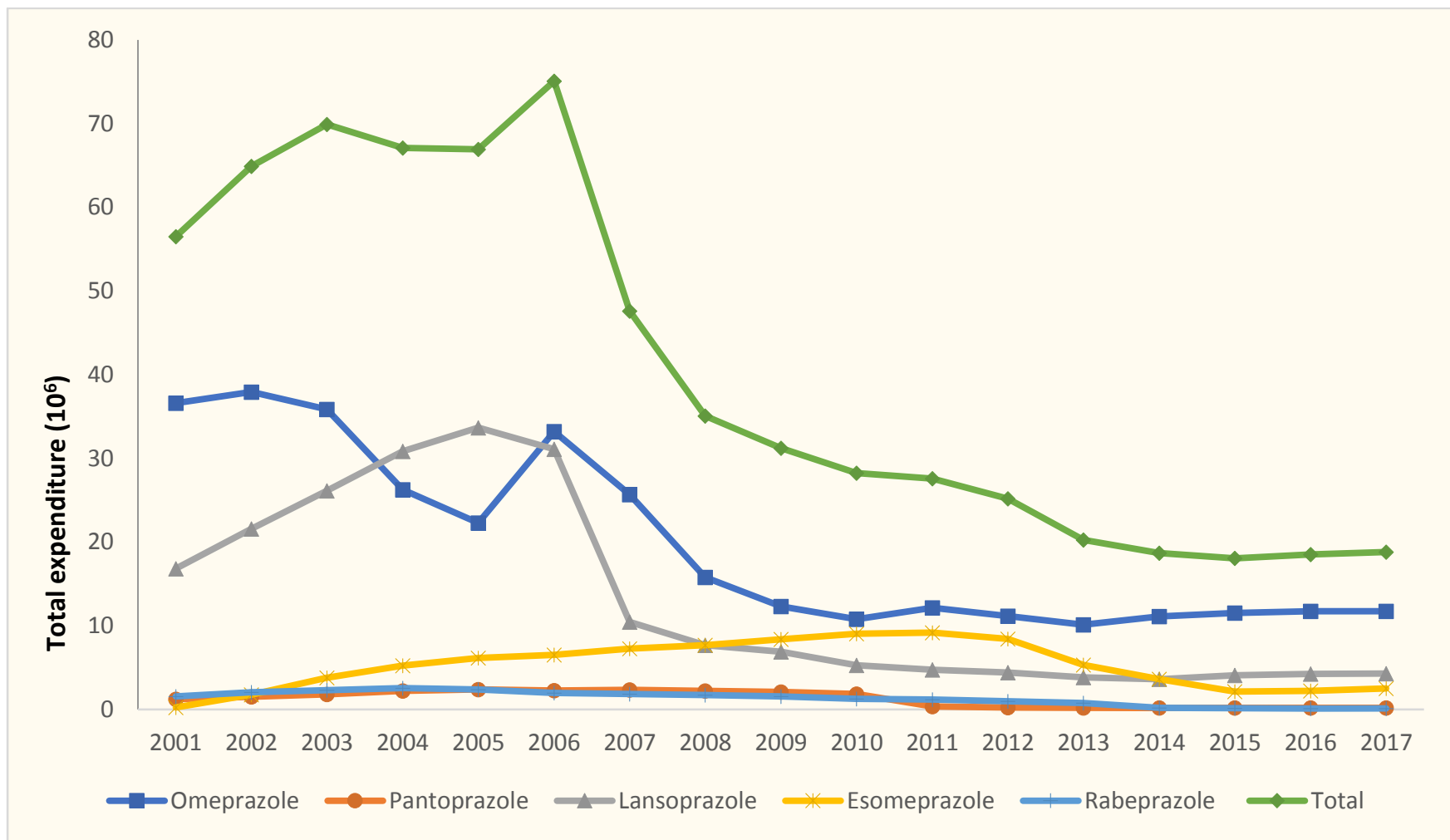

NB. Expenditure is based on Gross Ingrenient Costs (GIC)

As seen in Figure 2, PPI expenditure peaked in 2006 before falling rapidly with the availability of both generic omeprazole (2002) and generic lansoprazole (2005) at falling prices (Figure 3) combined with high rates of INN prescribing in Scotland even when only originators are available. Table 3 contains details of the percentage reduction in cost/ items dispensed for the different PPIs in 2017 versus their prices just before patent loss (Table 1). 
Figure 3-PPI Cost per item dispensed for the different PPIs 2001 to 2017 [Source ISD Scotland (63)]

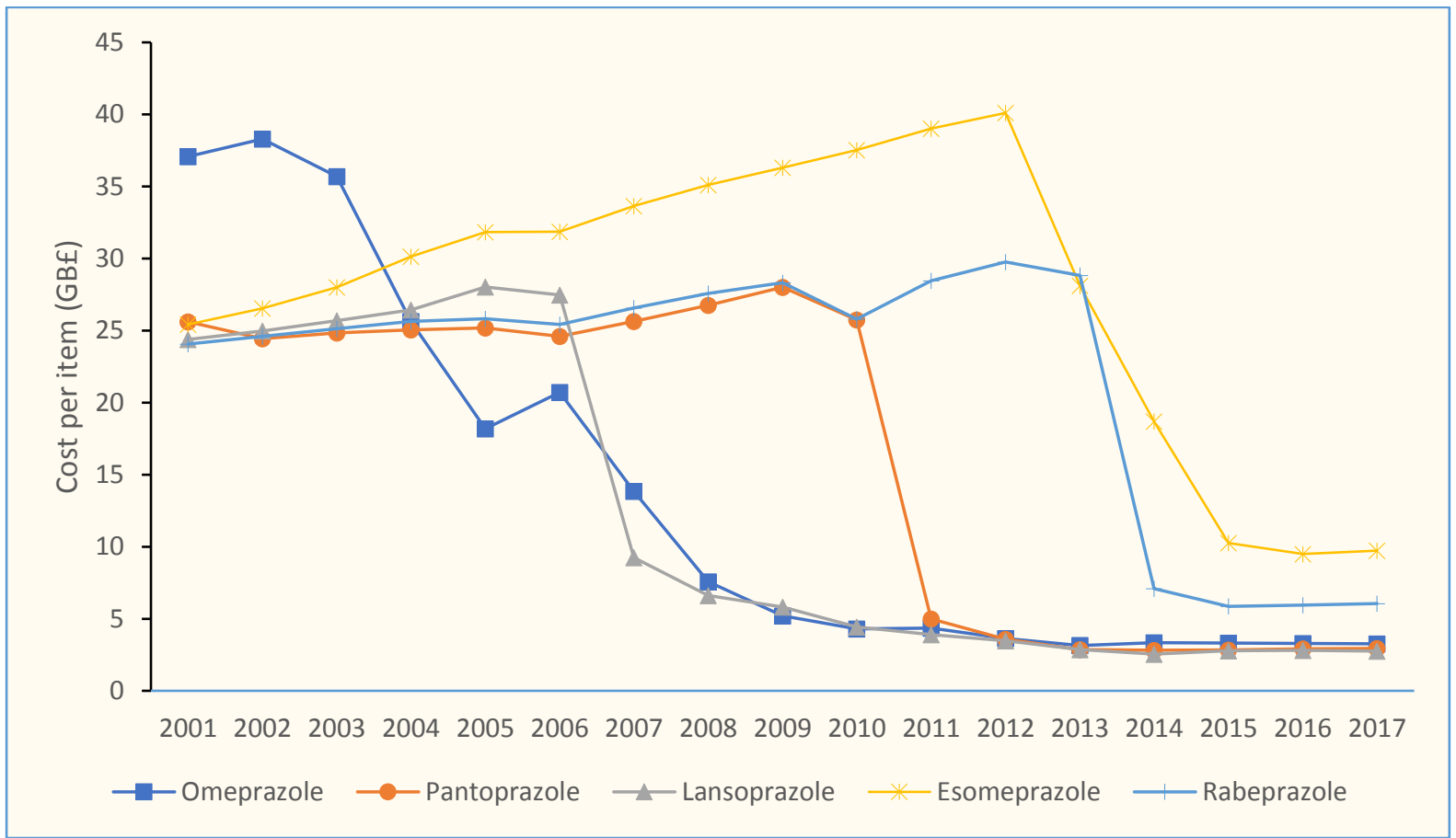

INN prescribing in terms of items dispensed varied between 96.7 and $99.1 \%$ for omeprazole in recent years versus $87.3 \%$ to $100 \%$ for pantoprazole, $92.6 \%$ to $99 \%$ for lansoprazole, $63.5 \%$ to $98 \%$ for esomeprazole and $42.6 \%$ to $96 \%$ for rabeprazole. As a result, the cost/ item dispensed for the various PPIs appreciably reduced following the launch of generics (Table 3).

Table 3 - Price reduction in cost/ item dispensed for the various PPIs in 2017 versus their prices just before patent loss [Source ISD Scotland - (63)]

\begin{tabular}{|l|c|}
\hline Proton Pump Inhibitor & \% reduction in 2017 \\
\hline Omeprazole & $91.5 \%$ \\
\hline Lansoprazole & $90.1 \%$ \\
\hline Pantoprazole & $89.5 \%$ \\
\hline Rabeprazole & $79.6 \%$ \\
\hline Esomeprazole & $73.2 \%$ \\
\hline
\end{tabular}

There appears to be a greater reduction in the prescribing of higher strength omeprazole in recent years versus lansoprazole as the two most prescribed PPIs (Figures 1, 4, 5), with the dispensing of omeprazole further analysed in DDDs. 
Figure 4 - Extent of high vs. lower strength PPI prescribing based on items dispensed 2001 to 2015 omeprazole and lansoprazole [Source ISD Scotland - (63)]

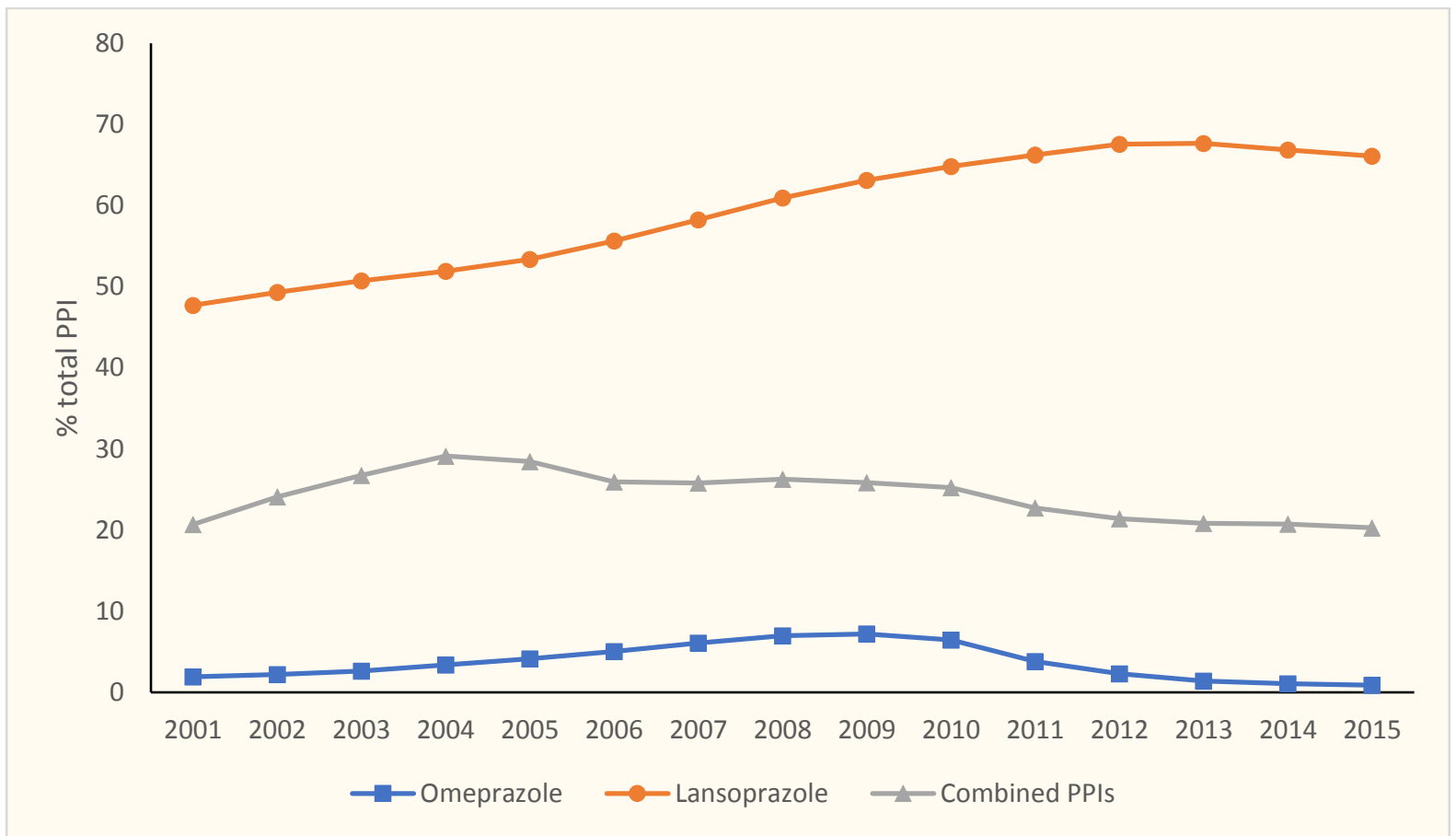

Figure 5 - Items dispensed (20 and 40mg omeprazole) and DDDs 2001 to 2017 [Source ISD Scotland - (63)]

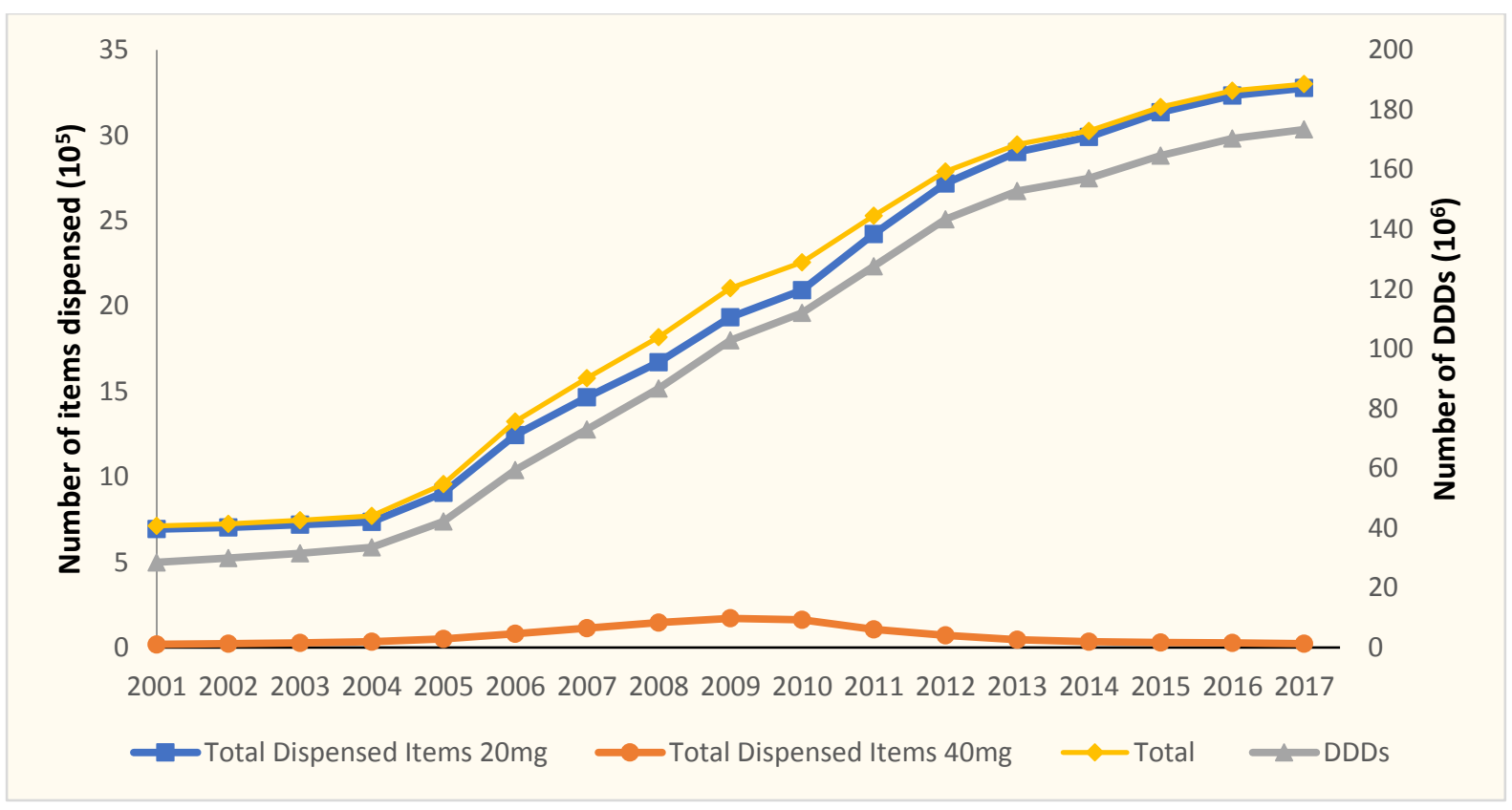

\section{Discussion}

We believe the appreciably increased prescribing of PPIs over the years (Figure 1) has been influenced by the high prevalence of dyspepsia in the UK, concerns with the extent of admissions to UK hospitals due to GI bleeding, increasing elderly patients increasing the extent of polypharmacy and the need for anti-coagulation as well as studies demonstrating the effectiveness of PPIs versus $\mathrm{H} 2$ antagonists in preventing as well as healing ulcers $(6,9,10,12,17,18,73-75)$. However, we cannot say with certainty without further qualitative research.

Similar to the findings with lipid lowering agents (62), the loss of a patent appears to appreciably influence subsequent prescribing patterns not only omeprazole following generic availability in 2002 
(Table 1) but also for the other PPIs (Figure 1). The use of lansoprazole stabilised following the availability of generic omeprazole and then rose following the availability of generic lansoprazole (2006/ 2007 onwards - Figure 1). This was helped by the endorsement of generic lansoprazole in Regional Health Board Formularies (Table 2). The utilisation of the other PPIs remained low over the years, enhanced by recommendations not to prescribe (Table 2, Figure 1). Such activities followed appreciable price differences for omeprazole and lansoprazole versus for instance esomeprazole until recent years (Figure 3, Table 3). These price differences are hidden from patients as there is currently no co-payment in Scotland; however, prices do have an indirect effect as appreciable price differences between different medicines in a class can result in extensive educational and other activities by the Scottish government and the Regional Health Boards to influence subsequent prescribing without compromising care (Table 2). As a result of the various initiatives, the utilisation of omeprazole rose 3.66 times between 2001 and 2017, greater than the overall increase in PPI utilisation (3.06 times). During this time, expenditure on PPIs fell by $66.7 \%$ to just GB£18.832 million in 2017, aided by multiple initiatives (Table 2) combined with an appreciable reduction in prices following generic availability (Table 3 ).

Overall, the multiple demand-side measures (Table 2) appear to have successfully moderated or even reduce the prescribing of higher cost PPIs that are perceived to have no additional benefits (Figures 1 and 2). In addition, continuing to encourage high INN prescribing. High INN prescribing in Scotland is also seen in other disease areas including anti-coagulants, anti-depressants, statins for hypercholesterolaemia, anti-hypertensives and atypical antipsychotics for schizophrenia $(48,62,76-$ 78). As a result, providing exemplars to other European countries where there are concerns with generics $(58,59)$. In addition, providing examples to other European countries with currently limited demand side measures resulting in the continued prescribing of higher priced patented medicines with limited additional benefits $(47,48,79)$. This again shows how generic and patented medicines do interact with each other, and affect the way they are prescribed in Scotland, building on the recent findings with the lipid lowering therapies (62). Again, multiple demand-side measures (Table 2) appeared necessary to effect changes in prescribing habits, similar to other studies $(25,62,80-82)$.

As older PPIs lose their patent and become cheaper, moving away from patented formulations in favour of generic PPIs with similar efficacy and safety profiles can be a reality. This can lead to substantial additional savings within the NHS system despite appreciably increasing volumes (Figures 1 and 2), although further savings can still be achieved (72). These savings can be used to fund the increased use of new valued but higher priced medicines as well as funding the increasing use of medicines in Scotland due to ageing populations within current budgets.

There has been some change in the prescribing of lower strength PPIs in recent years following the instigation of quality indicators and other initiatives to improve the quality of PPI prescribing (Table 2, Figures 4 and 5). However, it is difficult to make any definite statements since GPs in Scotland have typically prescribed two $20 \mathrm{mg}$ tablets as opposed to one $40 \mathrm{mg}$ tablet of omeprazole as this was cheaper. Having said this, the prescribing of $40 \mathrm{mg}$ omeprazole appears to have appreciably fallen in recent years whilst the prescribing of $20 \mathrm{mgs}$ has continued to rise causing the DDDs to continue to rise (Figure 5). This would suggest some improvement in the quality of prescribing if patients can be adequately managed on $20 \mathrm{mg}$ of omeprazole and $15 \mathrm{mg}$ lansoprazole, which is the case for prophylaxis in patients on NSAIDs or anti-platelet medicines. This is expected to decrease complications from long-term use of PPIs based on available evidence $(19,27,38,39,41)$.

We are aware of a number of limitations with this study. The major ones are the fact that we cannot link prescribing of PPIs to any diagnoses with this dataset. In addition, there can be differences between prescribing and dispensing data. We also could not measure adherence rates, which can be a concern among patients on PPIs (83). In addition, we could not measure any improvements in longterm outcomes from reduced prescribing of high dose PPIs with the administrative data sets we used. This would need access to patient level data and linked datasets. We are also aware we used GIC costs which includes a small discount before pharmacists are paid. Lastly, as mentioned, we principally used items dispensed rather than DDDs, which may lead to differences in interpretation if we had used DDDs. Never-the-less, we believe our findings are robust providing guidance for the future. 


\section{Conclusion}

Multiple measures in Scotland in recent years including those affecting the prices of medicines as well as their usage appreciably increased the prescribing of generic (multiple sourced) PPIs versus onpatent PPIs once they became available. This led to appreciably reduced expenditure on PPIs in recent years despite utilisation increasing over three-fold. There has been some reduction in the prescribing of higher strength PPIs in view of concerns with their long term safety; however, this needs further investigation before any definitive statements can be made. Overall, we believe these multiple activities in Scotland can be an exemplar for other countries seeking to enhance their prescribing efficiency.

\section{Funding}

The production of this paper was facilitated by a grant to Alec Morton by the University of Strathclyde under the university's New Professors' Fund.

\section{Conflicts of interest}

Marion Bennie, Simon Hurding, and Sean Macbride Stewart are all employed by NHS Scotland. The authors have no other conflicts of interest to declare.

\section{References}

1. Mares-Garcia E, Palazon-Bru A, Martinez-Martin A, Folgado-de la Rosa DM, Pereira-Exposito A, Gil-Guillen VF. Non-guideline-recommended prescribing of proton pump inhibitors in the general population. Current medical research and opinion. 2017;33(10):1725-9.

2. Godman B, Shrank W, Andersen M, Berg C, Bishop I, Burkhardt T, et al. Policies to enhance prescribing efficiency in europe: findings and future implications. Frontiers in pharmacology. 2010;1:141.

3. Woerkom M, Piepenbrink H, Godman B, Metz J, Campbell S, Bennie M, et al. Ongoing measures to enhance the efficiency of prescribing of proton pump inhibitors and statins in The Netherlands: influence and future implications. Journal of comparative effectiveness research. 2012;1(6):527-38.

4. $\quad$ NHS Scotland. Polypharmacy Guidance 2018. Available at URL:

http://www.therapeutics.scot.nhs.uk/wp-content/uploads/2017/10/Polypharmacy-Indicators.pdf.

5. Garuoliene K, Godman B, Gulbinovic J, Schiffers K, Wettermark B. Differences in utilization rates between commercial and administrative databases: implications for future health-economic and cross-national studies. Expert review of pharmacoeconomics \& outcomes research. 2016;16(2):14952.

6. Hungin AP, Hill C, Raghunath A. Systematic review: frequency and reasons for consultation for gastro-oesophageal reflux disease and dyspepsia. Alimentary pharmacology \& therapeutics. 2009;30(4):331-42.

7. Leontiadis GI, Sreedharan A, Dorward S, Barton P, Delaney B, Howden CW, et al. Systematic reviews of the clinical effectiveness and cost-effectiveness of proton pump inhibitors in acute upper gastrointestinal bleeding. Health technology assessment. 2007;11(51):iii-iv, 1-164.

8. Barkun AN, Adam V, Martel M, Bardou M. Cost-effectiveness analysis: stress ulcer bleeding prophylaxis with proton pump inhibitors, H2 receptor antagonists. Value in health. 2013;16(1):14-22.

9. Sigterman KE, van Pinxteren B, Bonis PA, Lau J, Numans ME. Short-term treatment with proton pump inhibitors, $\mathrm{H} 2$-receptor antagonists and prokinetics for gastro-oesophageal reflux disease-like symptoms and endoscopy negative reflux disease. The Cochrane database of systematic reviews. 2013(5):Cd002095.

10. Whealon SR, Gibbs L. What is the optimal duration of PPI therapy for healing a gastric or duodenal ulcer? THE JOURNAL OF FAMILY PRACTICE. 2015;64(12):805-13.

11. Domingues G, Moraes-Filho JP. Noncompliance is an impact factor in the treatment of gastroesophageal reflux disease. Expert review of gastroenterology \& hepatology. 2014;8(7):761-5. 12. Robinson M, Horn J. Clinical pharmacology of proton pump inhibitors: what the practising physician needs to know. Drugs. 2003;63(24):2739-54.

13. Mo C, Sun G, Lu M-L, Zhang L, Wang Y-Z, Sun X, et al. Proton pump inhibitors in prevention of low-dose aspirin-associated upper gastrointestinal injuries. World journal of gastroenterology. 2015;21(17):5382-92. 
14. NHS Scotland. National Therapeutic Indicators 2015/ 2016. Available at URL:

file:///C:/Users/mail/Desktop/My\%20documents/Ongoing\%20papers/Scotland\%20PPIs/Therapeutic\% 20indicators\%202015\%20to\%202016.pdf.

15. Clinical Knowledge Summaries. NSAIDs - prescribing issues. 2015. Available at URL: https://cks.nice.org.uk/nsaids-prescribing-issues\#!scenario.

16. NHS Scotland. National Therapeutic Indicators 2014/ 2015. Available at URL:

http://www.sehd.scot.nhs.uk/publications/DC20141201nti.pdf

17. Pirmohamed M, James S, Meakin S, Green C, Scott AK, Walley TJ, et al. Adverse drug reactions as cause of admission to hospital: prospective analysis of 18820 patients. BMJ : British Medical Journal. 2004;329(7456):15-9.

18. Siau K, Chapman W, Sharma N, Tripathi D, Iqbal T, Bhala N. Management of acute upper gastrointestinal bleeding: an update for the general physician. J R Coll Physicians Edinb 2017; 47: 218-30

19. NHS Greater Glasgow and Clyde. Medicines Update Extra. ORAL PROTON PUMP INHIBITORS. 2015. Available at URL:

http://www.ggcprescribing.org.uk/media/uploads/ps_extra/mu_extra_04_-_2015.pdf.

20. Heidelbaugh JJ, Goldberg KL, Inadomi JM. Overutilization of proton pump inhibitors: a review of cost-effectiveness and risk [corrected]. The American journal of gastroenterology. 2009;104 Suppl 2:S27-32.

21. Ramirez E, Lei SH, Borobia AM, Pinana E, Fudio S, Munoz R, et al. Overuse of PPIs in patients at admission, during treatment, and at discharge in a tertiary Spanish hospital. Current clinical pharmacology. 2010;5(4):288-97.

22. Ntaios G, Chatzinikolaou A, Kaiafa G, Savopoulos C, Hatzitolios A, Karamitsos D. Evaluation of use of proton pump inhibitors in Greece. European journal of internal medicine. 2009;20(2):171-3. 23. Eid SM, Boueiz A, Paranji S, Mativo C, Landis R, Abougergi MS. Patterns and predictors of proton pump inhibitor overuse among academic and non-academic hospitalists. Internal medicine. 2010;49(23):2561-8.

24. Fraeyman J, Van Hal G, Godman B, Beutels P. The potential influence of various initiatives to improve rational prescribing for proton pump inhibitors and statins in Belgium. Expert review of pharmacoeconomics \& outcomes research. 2013;13(1):141-51.

25. Godman B, Wettermark B, van Woerkom M, Fraeyman J, Alvarez-Madrazo S, Berg C, et al. Multiple policies to enhance prescribing efficiency for established medicines in Europe with a particular focus on demand-side measures: findings and future implications. Frontiers in pharmacology. 2014;5:106.

26. Godman B, Fadare J. Non-guideline-recommended prescribing of proton pump inhibitors: implications for the future and reducing over usage. Current medical research and opinion. 2017;33(11):2085-7.

27. NHS Scotland. National Therapeutic Indicators. 2012 - Baseline data. Available at URL: http://www.sehd.scot.nhs.uk/pca/PCA2012(M)08report.pdf.

28. Freedberg DE, Lamousé-Smith ES, Lightdale JR, Jin Z, Yang Y-X, Abrams JA. Use of Acid Suppression Medication is Associated With Risk for C. difficile Infection in Infants and Children: A Population-based Study. Clinical Infectious Diseases. 2015;61(6):912-7.

29. Prag C, Prag M, Fredlund H. Proton pump inhibitors as a risk factor for norovirus infection. Epidemiology and infection. 2017:1-7.

30. Lambert AA, Lam JO, Paik JJ, Ugarte-Gil C, Drummond MB, Crowell TA. Risk of CommunityAcquired Pneumonia with Outpatient Proton-Pump Inhibitor Therapy: A Systematic Review and MetaAnalysis. PloS one. 2015;10(6):e0128004.

31. Bavishi C, Dupont HL. Systematic review: the use of proton pump inhibitors and increased susceptibility to enteric infection. Alimentary pharmacology \& therapeutics. 2011;34(11-12):1269-81. 32. Jacob L, Hadji P, Kostev K. The use of proton pump inhibitors is positively associated with osteoporosis in postmenopausal women in Germany. Climacteric. 2016;19(5):478-81.

33. Lazarus B, Chen Y, Wilson FP, Sang Y, Chang AR, Coresh J, et al. Proton Pump Inhibitor Use and Risk of Chronic Kidney Disease. JAMA internal medicine. 2016;176(2):238-46.

34. Danziger J, William JH, Scott DJ, Lee J, Lehman LW, Mark RG, et al. Proton-pump inhibitor use is associated with low serum magnesium concentrations. Kidney international. 2013;83(4):692-9. 35. Wise J. Gastric acid suppressants are associated with risk of $<\mathrm{em}>\mathrm{C}$ difficile $</ \mathrm{em}>$ infection. BMJ. 2017;356.

36. Trifan A, Stanciu C, Girleanu I, Stoica OC, Singeap AM, Maxim R, et al. Proton pump inhibitors therapy and risk of Clostridium difficile infection: Systematic review and meta-analysis. World Journal of Gastroenterology. 2017;23(35):6500-15. 
37. Imhann F, Bonder MJ, Vich Vila A, Fu J, Mujagic Z, Vork L, et al. Proton pump inhibitors affect the gut microbiome. Gut. 2015.

38. MHRA. Proton pump inhibitors in long-term use: increased risk of fracture. Available at URL: https://www.gov.uk/drug-safety-update/proton-pump-inhibitors-in-long-term-use-increased-risk-offracture.

39. MHRA. Proton pump inhibitors in long-term use: reports of hypomagnesaemia. Available at URL: https://www.gov.uk/drug-safety-update/proton-pump-inhibitors-in-long-term-use-reports-ofhypomagnesaemia.

40. NHS Scotland. Scottish Health Protection Network Scottish Guidance No 6,2017 edition. Guidance on Prevention and Control of Clostridium difficile Infection (CDI) in health and social care settings in Scotland. Available at URL: http://www.hps.scot.nhs.uk/resourcedocument.aspx?id=6188. 41. Lothian Joint Formulary. Proton Pump Inhibitors (PPIs) an information leaflet for patients. Available at URL:

http://www.ljf.scot.nhs.uk/PatientZone/PatientInformationLeaflets/PILs/Proton\%20Pump\%20Inhibitors \%20(PPIs)\%20PIL\%20v3\%20\%20LOT1333.pdf.

42. NHS Lothian. LOTHIAN PRESCRIBING BULLETIN. April/ May 2008. Available at URL: file:///C:/Users/mail/Desktop/My\%20documents/Ongoing\%20papers/Scotland\%20PPIs/LPB\%20lssue $\% 20$ No\%2032\%20-\%20FINAL.pdf.

43. NHS Lothian. LOTHIAN PRESCRIBING BULLETIN. Issue 26. April/ May 2007. Available at URL: http://www.ljf.scot.nhs.uk/PrescribingBulletins/2007/lpb/LPB\%20lssue\%20No\%2026.pdf.

44. Audit Scotland. Supporting prescribing in general practice - a progress report. June 2003. Available at URL: http://www.audit-

scotland.gov.uk/docs/health/2003/nr_030626_supporting_prescribing_km.pdf.

45. NHS Scotland. The Scottish Government. National Therapeutic Indicators 2013 - Baseline Report. Available at URL:

file:///C:/Users/mail/Desktop/My\%20documents/Ongoing\%20papers/Scotland\%20PPIs/National\%20T herapeutic\%20Indicators\%20Scotland\%202013.pdf.

46. NHS Scotland, The Scottish Government. National Therapeutic Indicators and Additional Prescribing Measures 2016/2017. Available at URL:

file://C:/Users/mail/Desktop/My\%20documents/Ongoing\%20papers/Scotland\%20PPIs/NTI-16-17-

Baseline-Report-Final-Version.pdf

47. Godman B, Shrank W, Andersen M, Berg C, Bishop I, Burkhardt T, et al. Comparing policies to enhance prescribing efficiency in Europe through increasing generic utilization: changes seen and global implications. Expert review of pharmacoeconomics \& outcomes research. 2010;10(6):707-22.

48. Godman B, Bishop I, Finlayson AE, Campbell S, Kwon HY, Bennie M. Reforms and initiatives in Scotland in recent years to encourage the prescribing of generic drugs, their influence and implications for other countries. Expert review of pharmacoeconomics \& outcomes research. 2013;13(4):469-82.

49. Bennie M, Godman B, Bishop I, Campbell S. Multiple initiatives continue to enhance the prescribing efficiency for the proton pump inhibitors and statins in Scotland. Expert review of pharmacoeconomics \& outcomes research. 2012;12(1):125-30.

50. McGinn D, Godman B, Lonsdale J, Way R, Wettermark B, Haycox A. Initiatives to enhance the quality and efficiency of statin and PPI prescribing in the UK: impact and implications. Expert review of pharmacoeconomics \& outcomes research. 2010;10(1):73-85.

51. LOTHIAN PRESCRIBING BULLETIN. April/ May 2003. Available at URL:

http://www.ljf.scot.nhs.uk/PrescribingBulletins/2003/lpb/LPB\%20lssue\%20No\%202.pdf.

52. Ferner RE, Lenney W, Marriott JF. Controversy over generic substitution. BMJ. 2010;340:c2548.

53. Godman B, Abuelkhair M, Vitry A, Abdu S, Bennie M, Bishop I et al. Payers endorse generics to enhance prescribing efficiency: impact and future implications, a case history approach.

2012;1(2):69-83.

54. Godman B, Wettermark B, Hoffmann M, Andersson K, Haycox A, Gustafsson LL. Multifaceted national and regional drug reforms and initiatives in ambulatory care in Sweden: global relevance.

Expert review of pharmacoeconomics \& outcomes research. 2009;9(1):65-83.

55. Simoens S. A reviewof generic medicine pricing in Europe. Generics and Biosimilar Journal. 2012;1(1):8-12.

56. Duerden MG, Hughes DA. Generic and therapeutic substitutions in the UK: are they a good thing? British journal of clinical pharmacology. 2010;70(3):335-41. 
57. MHRA. Antiepileptic drugs: updated advice on switching between different manufacturers' products. 2017. Available from URL: https://www.gov.uk/drug-safety-update/antiepileptic-drugsupdated-advice-on-switching-between-different-manufacturers-products\#chm-review-and-update. 58. Dunne SS, Shannon B, Cullen W, Dunne CP. Beliefs, perceptions and behaviours of GPS towards generic medicines. Fam Pract. 2014;31(4):467-74.

59. Labiris G, Fanariotis M, Kastanioti C, Alexias G, Protopapas A, Karampitsakos T, et al. Greek Physicians' Perceptions on Generic Drugs in the Era of Austerity. Scientifica. 2015;2015:251792.

60. NHS Lothian Joint Formulary. 1.3 Antisecretory drugs and mucosal protectants. Available at URL: http://www.ljf.scot.nhs.uk/LothianJointFormularies/Adult/1.0/1.3/Pages/default.aspx.

61. NHS Greater Glasgow and Clyde. Post Script Extra - 6, April 2008. ORAL PROTON PUMP INHIBITORS. Available at URL:

file:///C:/Users/mail/Desktop/My\%20documents/Ongoing\%20papers/Scotland\%20PPIs/GGC\%20April $\% 202006 \% 20 P P I s$.pdf.

62. Leporowski A, Godman B, Kurdi A, MacBride-Stewart S, Ryan M, Hurding S, et al. Ongoing activities to optimize the quality and efficiency of lipid-lowering agents in the Scottish national health service: influence and implications. Expert review of pharmacoeconomics \& outcomes research. 2018;18(6):655-66.

63. ISD Scotland. Community Dispensing. Prescription Cost Analysis. Published July 2018. Available at URL: Available at URL: http://isdscotland.org/Health-Topics/Prescribing-andMedicines/Community-Dispensing/Prescription-Cost-Analysis/.

64. WHO. WHO Collaborating Centre for Drug Statistics Methodology. ATC/ DDD Index. Available at URL: https://www.whocc.no/

65. Wettermark B, Godman B, Jacobsson B, Haaijer-Ruskamp FM. Soft regulations in pharmaceutical policy making: an overview of current approaches and their consequences. Applied health economics and health policy. 2009;7(3):137-47.

66. Martikainen JE, Saastamoinen LK, Korhonen MJ, Enlund H, Helin-Salmivaara A. Impact of restricted reimbursement on the use of statins in Finland: a register-based study. Medical care. 2010;48(9):761-6.

67. Godman B, Burkhardt T, Bucsics A, Wettermark B, Wieninger P. Impact of recent reforms in Austria on utilization and expenditure of PPIs and lipid-lowering drugs: implications for the future. Expert review of pharmacoeconomics \& outcomes research. 2009;9(5):475-84.

68. Godman B, Sakshaug S, Berg C, Wettermark B, Haycox A. Combination of prescribing restrictions and policies to engineer low prices to reduce reimbursement costs. Expert review of pharmacoeconomics \& outcomes research. 2011;11(1):121-9.

69. Pettersson B, Hoffmann M, Wandell P, Levin LA. Utilization and costs of lipid modifying therapies following health technology assessment for the new reimbursement scheme in Sweden. Health policy. 2012;104(1):84-91.

70. Zhang F, Wagner AK, Ross-Degnan D. Simulation-based power calculation for designing interrupted time series analyses of health policy interventions. Journal of clinical epidemiology. 2011;64(11):1252-61.

71. NHS Lothian. Issue 23. October/ November 2006. Available at URL: http://www.ljf.scot.nhs.uk/PrescribingBulletins/2006/lpb/LPB\%20lssue\%20No\%2023.pdf.

72. Audit Scotland. Prescribing in general practice in Scotland. 2013. Available at URL: file://C:/Users/mail/Desktop/My\%20documents/Ongoing\%20papers/Scotland\%20PPIs/2013\%20Audit $\% 20$ Scotland.pdf.

73. Pink J, Lane S, Pirmohamed M, Hughes DA. Dabigatran etexilate versus warfarin in management of non-valvular atrial fibrillation in UK context: quantitative benefit-harm and economic analyses. BMJ. 2011;343:d6333.

74. Marshall S, Fearon P, Dawson J, Quinn TJ. Stop the clots, but at what cost? Pharmacoeconomics of dabigatran etexilate for the prevention of stroke in subjects with atrial fibrillation: a systematic literature review. Expert review of pharmacoeconomics \& outcomes research. 2013;13(1):29-42.

75. Slater N, White S, Venables R, Frisher M. Factors associated with polypharmacy in primary care: a cross-sectional analysis of data from The English Longitudinal Study of Ageing (ELSA). BMJ open. 2018;8(3):e020270.

76. Bennie M, Bishop I, Godman B, Campbell S, Miranda J, Finlayson AE, et al. Are prescribing initiatives readily transferable across classes: the case of generic losartan in Scotland? Quality in primary care. 2013;21(1):7-15. 
77. Bennie M, Bishop I, Godman B, Barbui C, Raschi E, Campbell S, et al. Are specific initiatives required to enhance prescribing of generic atypical antipsychotics in Scotland?: International implications. International journal of clinical practice. 2013;67(2):170-80.

78. Baumgärtel C, Godman B, Malmström R, Andersen M, Abuelkhair M, Abdu S et al. What lessons can be learned from the launch of generic clopidogrel? GaBI Journal. 2012;1(2):58-68.

79. Voncina L, Strizrep T, Godman B, Bennie M, Bishop I, Campbell S, et al. Influence of demand-side measures to enhance renin-angiotensin prescribing efficiency in Europe: implications for the future. Expert review of pharmacoeconomics \& outcomes research. 2011;11(4):469-79.

80. Barton S. Using clinical evidence. BMJ. 2001;322(7285):503-4.

81. Bero LA, Grilli R, Grimshaw JM, Harvey E, Oxman AD, Thomson MA. Closing the gap between research and practice: an overview of systematic reviews of interventions to promote the implementation of research findings. The Cochrane Effective Practice and Organization of Care Review Group. BMJ. 1998;317(7156):465-8.

82. Furst J, Cizman M, Mrak J, Kos D, Campbell S, Coenen S, et al. The influence of a sustained multifaceted approach to improve antibiotic prescribing in Slovenia during the past decade: findings and implications. Expert review of anti-infective therapy. 2015;13(2):279-89.

83. Mares-Garcia E, Palazon-Bru A, Folgado-de la Rosa DM, Pereira-Exposito A, Martinez-Martin A, Cortes-Castell E, et al. Construction, internal validation and implementation in a mobile application of a scoring system to predict nonadherence to proton pump inhibitors. PeerJ. 2017;5:e3455. 